\title{
PENYEBAB PECAHNYA CYLINDER LINER PADA GENERATOR ENGINE DI MT. MARTHA OPTION
}

\author{
A. Y Prasetya ${ }^{a}$, Tri Kismantoro ${ }^{b}$ \\ ${ }^{a}$ Taruna Program Studi Teknika PIP Semarang \\ ${ }^{b}$ Dosen Program Studi Nautika PIP Semarang
}

\begin{abstract}
ABSTRAK
Generator Engine merupakan mesin penghasil daya listrik utama di kapal, mesin ini harus mendapat perhatian dan perawatan secara intensif, salah satunya adalah pada cylinder liner karena cylinder liner adalah bagian dari ruang bakar mesin diesel yang penting sebagai tempat terjadinya pembakaran bahan bakar dengan udara dan juga alur gerak bolak-balik piston. Akibat gerakan tersebut akan terjadi gesekan antara cylinder liner dan cincin piston yang menyebabkan keausan pada dinding cylinder liner. Kondisi cylinder liner yang telah aus dan tekanan air pendingin yang kurang adalah faktor utama penyebab pecahnya pada cylinder liner. Upaya untuk mencegah pecahnya cylinder liner adalah perawatan dan perhatian pada sistim pelumasan dan pendinginannya. Perawatan dan perbaikan terhadap cylinder liner dilakukan sesuai jam kerja yang telah ditentukan sesuai manual book, dengan adanya perawatan yang rutin maka pecahnya cylinder liner dapat diminimalisir dan generator engine dapat bekerja normal.
\end{abstract}

Kata kunci : faktor penyebab pecahnya cylinder liner, dampak pecahnya cylinder liner, upaya pencegahan pecahnya cylinder liner

\section{PENDAHULUAN}

\section{A. Latar Belakang}

Dalam pengoperasian motor diesel diperlukan banyak daya listrik. Daya listrik digunakan untuk menggerakkan motor-motor dari peralatan bantu pada kamar mesin dan mesin-mesin geladak, lampu penerangan, sistem komunikasi dan navigasi, pengkondisian udara (AC) dan ventilasi, perlengkapan dapur (galley), sistem sanitari, alarm, sistem kebakaran dan sebagainya. Di sini generator engine sangat berperan penting untuk mencapai itu semua karena digunakan untuk menyuplai kebutuhan daya listrik di kapal. Daya yang dihasilkan generator engine diperoleh melalui pembakaran bahan bakar yang terjadi di dalam silinder.

Hal ini cylinder liner memegang peranan sangat penting, karena cylinder liner adalah komponen mesin yang dipasang pada cylinder block yang berfungsi sebagai tempat piston dan ruang bakar pada motor diesel. Pada saat langkah kompresi dan pembakaran akan dihasilkan tekanan dan temperatur gas yang tinggi, sehingga untuk mencegah kebocoran kompresi ini maka pada piston dipasang ring piston untuk memperkecil celah antara dinding cylinder liner dengan piston. Piston yang bergerak bolak-balik mengakibatkan keausan pada dinding cylinder liner bagian dalam, hal ini akan menimbulkan penambahan kelonggaran antara piston dan cylinder liner, sehingga dapat menyebabkan kebocoran gas, tekanan kompresi berkurang dan tenaga yang dihasilkan juga berkurang. Agar keausan cylinder liner tidak terlalu banyak maka diupayakan bahan yang digunakan tahanan aus dan juga tahan terhadap panas, karena cylinder liner yang baik dan tidak aus akan menghasilkan pembakaran yang sempurna.

Berdasarkan hal tersebut, maka penulis tertarik untuk menuliskan penelitian yang berjudul "Analisis Penyebab Pecahnya Cylinder Liner Pada Generator Engine di MT. Martha Option." 
A. Y Prasetya ${ }^{a}$ dan Tri Kismantoro ${ }^{b}$

\section{B. Perumusan Masalah}

Dari uraian di atas maka masalahmasalah yang akan dibahas adalah sebagai berikut:

a. Faktor apa saja yang menyebabkan pecahnya cylinder liner pada generator engine di MT. Martha Option?

b. Dampak yang ditimbulkan akibat pecahnya cylinder liner pada generator engine di MT. Martha Option?

c. Upaya apa yang dilakukan untuk mencegah pecahnya cylinder liner pada generator engine di MT. Martha Option?

\section{Tujuan Penelitian}

Tujuan dari penelitian adalah untuk mengetahui faktor prnyebab pecahnya cylinder liner, untuk menganalisa dampak pecahnya cylinder liner dan untuk menangani pecahnya cylinder liner pada generator engine dan menjelaskan bagaimana pemecahan masalah tersebut.

\section{TINJAUAN PUSTAKA}

\section{Pengertian komponen dasar generator engine}

a. Cylinder Liner

Adalah tempat terjadinya pembakaran yang menghasilkan tenaga atau usaha di dalam mesin dan tempat berlangsungnya proses kerja mesin langkah isap, kompresi, usaha, buang. Cylinder liner terbuat dari bahan baja tuang yang baik.

b. Cylinder head

Bersama piston dan cylinder liner membentuk ruang bakar. Menahan tekanan pembakaran yang tinggi. Menyalurkan panas ke cooling sistem.

c. Cylinder block

Cylinder block terbuat dari besi cor (cast iron) dan pembuatannya dilakukan dengan proses casting (pengecoran). Cylinder block merupakan rangka utama dari engine.

\section{d. Piston dan piston ring}

Piston ring berfungsi sebagai seal perapat untuk mencegah terjadinya kebocoran antara piston dengan dinding cylinder liner dan mencegah masuknya minyak pelumas ke dalam ruang bakar serta memindahkan sebagian besar panas piston ke dinding silinder.

e. Batang engkol (connecting rod) Batang engkol (connecting rod). Satu ujung, yang disebut ujung kecil dari batang engkol, dipasangkan kepada pena pergelangan (wrist pin) atau pena torak (piston pin) yang terletak di dalam torak. Batang engkol mengubah dan meneruskan gerak ulak-alik (reciprocating) dari torak menjadi putaran kontinu pena engkol selama langkah kerja dan sebaliknya selama langkah yang lain.(Maleev, 1995: 6)

f. Poros engkol (crankshaft)

Tenaga (torque) yang digunakan sebagai tenaga penggerak dihasilkan oleh gerakan batang torak dan dirubah menjadi gerak putaran pada poros engkol. Poros engkol menerima beban yang besar dari torak dan batang torak serta berputar pada kecepatan tinggi.

g. Roda gila (flywheel)

Manfaat roda gila adalah untuk menyimpan energi ketika energi yang dibangkitkan oleh gas dalam mesin lebih besar daripada beban mesin yaitu, selama langkah daya dan mengembalikannya kepada poros engkol ketika gas di dalam silinder tidak membangkitkan energi yaitu, selama langkah buang, hisap dan kompresi dalam mesin empat langkah, atau selama langkah kompresi dalam mesin dua langkah. Secara umum, kalau kecepatan poros engkol cenderung meningkat, roda gila menyerap energi, kalau cenderung menurun, roda gila memberikan energi kepada poros engkol. Jadi, roda gila bertugas memelihara putaran poros engkol pada kecepatan seragam.

Kenyataannya, roda gila memberikan beberapa manfaat menjaga variasi kecepatan yang tidak dapat dihindarkan selama tiap daur agar tetap dalam batas yang diinginkan, 
membatasi kenaikan atau penurunan sesaat dari kecepatan mesin selama perubahan bahan bakar meledak, membawa torak sampai melampaui tekanan kompresi ketika berjalan pada kecepatan rendah atau kecepatan tanpa kerja (idle), membantu kenaikan kecepatan mesin ketika start, dengan altrenator yang berjalan paralel, akan menjaga kemajuan atau kemunduran kecepatan sudut, dibandingkan dengan kecepatan sudut yang benar-benar seragam, agar tetap dalam batas yang diinginkan. (Maleev, 1995: 79)

h. Poros nok (camshaft)

Poros nok digerakkan oleh poros engkol oleh penggerak rantai atau oleh roda gigi pengatur waktu mengoperasikan katup pemasukan dan katup buang melalui nok, pengikut nok, batang dorong. Dan juga berguna untuk menggerakkan pompa bahan bakar tekanan tinggi untuk keperluan starting dan reversing (pembalik) camshaft digerakkan oleh roda gigi yang dihubungkan pada crank shaft.

\section{Sistem pada generator engine}

a. Sistem bahan bakar

Sistem bahan bakar dari instalasi motor diesel dijelaskan sebagai peralatan yang diperlukan untuk menangani minyak bahan bakar dari titik diserahkannya ke instalasi sampai mencapai pompa injeksi bahan bakar. Peralatan ini terdiri atas strainer dan saringan (filter), pompa transfer, tangki penyimpan dan tangki harian, indikator permukaan tanki bahan bakar, pemipaan dan meter bahan bakar.

Sifat bahan bakar berikut yang mempengaruhi prestasi dan keandalan dari suatu mesin diesel:

1) Penguapan (volatility)

Volatility adalah sifat kecenderungan bahan bakar untuk berubah fasa menjadi fasa uap.

2) Residu karbon

Residu karbon adalah karbon yang tertinggal setelah penguapan dan pembakaran habis suatu bahan yang diuapkan dari minyak.

3) Viskositas

Viskositas adalah tahanan yang dimiliki fluida yang dialirkan dalam pipa kapiler terhadap gaya gravitasi, biasanya dinyatakan dalam waktu yang diperlukan untuk mengalir pada jarak tertentu. Jika viskositas semakin tinggi, maka tahanan untuk mengalir akan semakin tinggi. Karakteristik ini sangat penting karena mempengaruhi kinerja injektor pada motor diesel.

4) Kandungan belerang

Belerang dalam sistem bahan bakar terbakar bersama minyak dan menghasilkan gas yang sangat korosif yang diembunkan oleh dinding cylinder liner yang didinginkan, terutama kalau mesin beroprasi dengan beban rendah dan suhu silinder menurun.

5) Abu (ash)

Abu (ash) adalah sumber dari bahan yang dapat menggerus yang akan mengakibatkan keausan mesin yang bersinggungan secara berlebihan dan dapat juga menyebabkan korosi.

6) Air dan endapan

Air dan endapan dapat mengakibatkan permasalah pada saat pembersihan bahan bakar, ignition delay, penyumbatan dan juga korosi.

7) Titik nyala (flash point)

Titik nyala adalah titik temperatur terendah dimana bahan bakar dapat menyala.

8) Mutu penyalaan (ignition)

Mutu penyalaan (ignition) adalah sifat dari bahan bakar motor diesel yang penting, terutama pada motor diesel putaran tinggi sangat menentukan mudahnya penyalaan dan start mesin dingin.

9) Titik tuang (pour point)

Titik tuang (pour point) adalah suhu minyak mulai membeku atau berhenti mengalir. 
A. Y Prasetya ${ }^{a}$ dan Tri Kismantoro ${ }^{b}$

10) Sifat korosif (corrosiveness)

Sifat korosif (corrosiveness), minyak bahan bakar tidak boleh korosif, tidak boleh mengandung asam bebas. Kalau tidak, maka dapat merusak permukaan logam yang bersinggungan pada mesin.

b. Sistem udara

Sistem udara start yaitu untuk menghidupkan sebuah motor diesel dengan udara ber tekanan $20 \mathrm{~s} / \mathrm{d} 30$ $\mathrm{kg} / \mathrm{cm}^{2}$. Terdiri dari kompresor, separator, main air receiver, reducing valve dan reducing station.

c. Sistem pemasukan udara

Sistem pemasukan udara yaitu memasukkan udara sebanyakbanyaknya ke dalam silinder dengan tekanan lebih dari 1 atm, tujuannya agar dalam proses pembakaran di dalam silinder tersedia cukup oksigen sehingga terjadi pembakaran yang sempurna dan berakibat pemakaian bahan bakar yang lebih hemat.

d. Sistem buang

Sistem buang adalah gabungan dari alat yang dilalui gas buang sisa pembakaran untuk meninggalkan motor diesel.

e. Sistem pelumasan

Adapun tujuan dari pelumasan tersebut adalah sebagai media pelumas diantara dua bagian yang bergerak, membentuk lapisan film minyak pada dua logam yang saling bergesekan, sebagai pelindung permukaan terhadap korosi, sebagai peredam suara dan sebagai penyalur panas gesekan.

f. Sistem pendinginan

Sistem pendingin marine engine sebagai penggerak utama kapal bergantung pada sistem pendingin air lautnya. Apabila aliran air laut ke penukar panas tidak lancar, bisa dipastikan panas yang dibawa coolant tidak bisa dibuang dengan baik karena media yang menjadi perpindahan panasnya tidak tersedia dengan cukup. Sistem pendinginan terbagi menjadi dua yaitu pendinginan tertutup dan pendinginan terbuka.

\section{METODE PENELITIAN}

Metode penelitian yang digunakan oleh penulis di dalam penyampaian masalah adalah diskriptif kualitatif, yaitu suatu metode yang digunakan untuk menemukan pengetahuan terhadap subjek penelitian pada suatu saat tertentu. Penelitian deskriptif merupakan penelitian yang dimaksudkan untuk mengumpulkan informasi mengenai subjek penelitian dan perilaku subjek penelitian pada suatu periode tertentu.

Penelitian deskriptif kualitatif berusaha menjadikan penelitian meliputi seluruh gejala atau keadaan yang ada, yaitu keadaaan gejala menurut apa adanya pada saat penelitian dilakukan. Metode ini menggambarkan dan menguraikan secara lugas dan sesuai dengan kenyataan yang ada tentang obyek yang diteliti.

Penelitian deskriptif tidak memerlukan administrasi yang rigit atau kaku, seperti keharusan pengontrolan terhadap suatu perlakuan. Dalam penelitian deskriptif kebanyakan tidak dimaksudkan untuk menguji hipotesis tertentu, tapi lebih mengambarkan "apa adanya" tentang subjek dalam social setting. Penelitian kualitatif deskriptif berusaha menemukan ssesuatu yang bearti sebagai alternatif dalam mengatasi sebuah masalah penelitian melalui prosedur ilmiah yang dapat dipertanggungjawabkan secara ilmiah. Penelitian deskriptif adalah penelitian yang dilakukan terhadap social setting dan subjek mandiri, yaitu tanpa membuat perbandingan, atau menghubungkan dengan social setting yang dan subjek yang berbeda. (Mukhtar, 2013: 11)

Waktu dan tempat penelitian yaitu selama penulis melaksanakan praktek kerja laut pada tanggal 07 Desember 2012 sampai dengan 14 Desember 2013 di MT. Martha Option milik PT. Waruna Nusa Sentana.

\section{HASIL PENELITIAN DAN PEMBAHASAN}

Penulis mencari penyebab timbulnya masalah dan menghubungkan antara hal yang satu dengan hal yang lainnya sehingga mudah dalam pemecahan masalahnya dengan faktafakta yang telah dijelaskan di atas. Untuk 
lebih mudah memahami penelitian ini maka penulis akan berusaha membahas faktor yang menyebabkan pecahnya sebuah cylinder liner, dampak yang ditimbulkan dari pecahnya cylinder liner dan upaya untuk menangani dan mencegah pecahnya cylinder liner.

1. Faktor penyebab pecahnya cylinder liner berpengaruh terhadap generator engine.

a. Kondisi cylinder liner sudah aus

Peningkatan temperatur yang terjadi pada ruang bakar menyebabkan terjadinya pemuaian material cincin piston dan lebih lanjut mengadakan tekanan ke dinding silinder. Hal ini juga menyumbang besarnya gaya gesek terhadap dinding silinder. Kekasaran permukaan bidang kontak antara dinding piston dengan silinder dan dengan adanya gaya gesek yang besar, menyebabkan keauasan pada dinding silinder semakin mudah. Material silinder memiliki sifat getas, lunak dan tidak tahan panas akan mudah keausan dinding silinder. Pemilihan bahan silinder sangat diawasi karena silinder memegang peranan penting lancarnya gerakan piston.(Tjahjono Tri, 2005:7879)

b. Gas buang tinggi

Suhu gas buang terlalu tinggi dan output mesin terlalu rendah. Alasan untuk ini dapat kebocoran pada cincin piston mesin, bocor katup buang, scavenging udara diblokir, misalnya filter hisap pada pendingin udara kotor atau blowers ruang mesin tidak menyediakan udara yang cukup, kegagalan Turbocharger karena fouling, sumbatan di sistem pembuangan dan tekanan udara yang sangat rendah.

Hal ini dapat diperiksa pada pistonring dan katup buang yang ketat dengan mengambil diagram kompresi. Pemeriksaan pada piston-ring dan katub buang cukup ketat jika rasio antara tekanan kompresi mutlak dan tekanan udara pemulungan mutlak adalah sama seperti itu selama pengujian. Dengan
Burmeister dan langkah mesin dua tak rasio ini adalah sekitar 30. (Christen knak. 1979: 97)

c. Tekanan air pendingin kurang

Tekanan air pendingin kurang maka yang dilakukan adalah mematikan kompresor udara jika kompresor tersebut sedang berjalan, drain atau membuang udara pada sistem pendinginan generator engine air pendingin sampai tekanan air kembali normal dan membersihkan fresh water cooler.

2. Dampak pecahnya cylinder liner berpengaruh terhadap generator engine.

a. Pembakaran dalam cylinder liner tidak sempurna.

Pembakaran mesin tidak sempurna dikarenakan masuknya sistem pendinginan pada ruang pembakaran yaitu campurnya udara, gas, dan air dan dapat mengakibatkan getaran mesin keras, tenaga kurang maksimal. Maka hal perlu dilakukan dalam mengatasi tersebut yaitu pengukuran dengan menggunakan diagram indikator pada indikator cook apa ada kelainan pada silinder, jika terjadi kelainan maka dilakukan over houl dan pengecekan carter oli generator engine, jika pada saat keadaan mati oil level normal dan ketika distart dan berjalan tiba-tiba penuh berarti ada kebocoran kompresi pada salah satu silinder. Dan segera lakukan perawatan pada silinder tersebut yang tlah diperiksa.

Menurut Nakoela dan Shoichi dalam buku serba guna (1995:28-29), kemungkinan terjadinya knocking adalah perbandingan kompresi terlalu tinggi sehingga suhu dan tekanan dari campuran udara bahan bakar cukup tinggi untuk dapat menyala dengan sendirinya, suhu dan tekanan campuran udara bahan bakar terlalu tinggi disebabkan pengisian yang terlalu banyak (super charging), kualitas bahan bakar (oktane number) yang cukup rendah akan menimbulkan terjadinya knocking. Untuk automobil digunakan 
A. Y Prasetya ${ }^{a}$ dan Tri Kismantoro ${ }^{\text {b }}$

bahan bakar bensin dengan oktane number 88-93, bentuk ruang bakar. Ruang bakar yang datar dan lebar pada motor pembakaran dengan katup sisi. Penyalaan spontan cenderung meningkatkan terjadinya knocking karena penyebaran api, pada motor dengan pendinginan udara kebanyakan cenderung terjadinya knocking. Dibanding dengan motor pendinginan air, karena pendinginannya kurang baik, bila gas diputar di dalam ruang bakar dan proses pembakaran dipercepat maka kemungkinan besar akan terjadi pembakaran yang normal dan sempurna. Knocking tidak akan terjadi dalam kasus seperti ini, pada kecepatan rendah dan beban berat, knocking cenderung akan terjadi karena suhu menjadi tinggi dan gas tidak cukup berputar atau bergerak dan campuran akan terbakar dengan lambat sehingga cenderung terjadinya knocking.

b. Merusak viscosity minyak lumas.

Tercampurnya miyak lumas dengan air disebabkan oleh pecahnya cylinder liner, air masuk ke bagian sistem oli mesin, mengakibatkan warna pada minyak lumas berubah menjadi putih susu dan viskositas minyak lumas menjadi encer, mesin akan mengalami kerusakan yang berat dan mengakibatkan korosi pada permukaan yang bersinggungan, untuk mencegah hal-hal tersebut antara lain pergantian minyak lumas atau diganti dengan minyak lumas yang baru dan pergantian atau over houl pada cylinder liner yang pecah.

3. Upaya untuk mencegah pecahnya cylinder liner.

a. Perbaikan pecahnya cylinder liner pada generator engine.

Reparasi keretakan pada cylinder oversize (http://joepencerahan.blogspot.com/2011/07/keru sakan-pada-cylinder-liner.html) terdiri dari:
1) Cara mekanis

Dibersihkan dengan kertas gosok, palu ketok, sikat baja atau dengan alat mekanik lainnya dengan memperhatikan permukaan cylinder head agar tidak terjadi kerusakan pada permukaannya.

2) Cara kimiawi

Dibersihkan dengan bahan kimia, yaitu larutan alkalin yang dicampur dengan bahan kimia lain seperti calcined soda, caustic soda, waterglass, sabun dan potasium bichromat dengan larutan kimia dengan komposisi tertentu dan jangka waktu tertentu, karena pada cylinder head terdapat lubang pendingin dan apabila terlalu lama direndam dalam larutan kimia akan merusak material. Larutan kimia berfungsi untuk melunakkan kerak karbon atau kotoran yang ada kemudian dibersihkan dengan sekrap kayu atau sikat yang kaku, agar tidak tergores maka tidak diijinkan menggunakan sikat kawat.

Dilakukan pengecekan pada permukaan cylinder oversize, apabila terjadi retak maka cylinder oversize harus diganti dengan yang baru meskipun hanya terjadi satu keretakan. Keretakan pada cylinder oversize dapat terjadi sebagai akibat tegangan akibat panas, bertambahnya tekanan cylinder liner, kesalahan pada sistem pendinginan, pukulan air, kerusakan mekanis, atau mutu material yang kurang baik. Sesuai dengan peraturan kelas, cylinder oversize tidak boleh dipakai kembali bila terjadi crack terbuka, karena dapat dilalui oleh air, uap atau gas keluar. Pada dasarnya jika keretakan terjadi maka kompresi dari mesin bocor dan akan menyebabkan keretakan itu semakin besar (retaknya membuka) dan dapat pecah. Oleh karena itu jika terjadi keretakan maka cylinder oversize harus diganti. 
b. Perawatan yang perlu dilakukan untuk mencegah pecahnya cylinder liner.

Menurut hasil observasi penulis pada saat praktek di kapal MT. Martha Option analisa perawatan perbaikan ini dilakukan apabila cylinder oversize masih dalam keadaan baik serta belum mengalami keausan maka cylinder oversize tersebut masih bisa dipakai namun ring Piston yang jam kerjanya sudah melewati batas waktu harus diganti atau di overhaul, demikian juga keadaaan minyak lumas harus senantiasa diperhatikan dan setiap satu bulan sekali dilakukan pemeriksaaan kualitas minyak lumas dengan sample untuk diperiksa di laboratorium darat.

Perawatan pada generator engine pada umumnya yaitu disesuaikan dengan jumlah jam kerja material dan metode perawatan sesuai dengan manual book, lakukan perawatan, pemeriksaan, pengukuran, perbaikan atau penggantian material sesuai jam kerja dan dari pengecekan fisik, dapat diambil keputusan material yang dirawat, diperbaiki atau diganti walau jam kerja belum terpenuhi/belum waktunya dilakukan penggantian material tersebut.

Tindakan yang perlu dilakukan untuk mencegah dan mengatasi pecahnya cylinder liner pada generator engine yaitu:

1) Perawatan pencegahan

Perawatan yang dilakukan sebelum cylinder liner mengalami keausan serta komponen-komponen lain yang membantu kerja dari cylinder liner sebelum mengalami keretakan atau kerusakan, maka dalam hal ini kita harus melakukan perawatan secara rutin, berkala dan terjadwal untuk menghindari terjadinya kerusakan ke arah yang lebih fatal.

2) Perawatan darurat

Perawatan yang dilakukan secara tiba-tiba tidak direncanakan dahulu. Perawatan dalam hal ini dilakukan dengan cara mencari penyebab kerusakan yang ditimbulkan secara mendadak dan selanjutnya secepat mungkin memperbaiki agar generator engine dapat beroperasi kembali.

3) Perawatan Berencana

Perawatan yang menentukan dan mempercayakan kepada seluruh prosedur perawatan yang dibuat oleh maker melalui Manual Instruction Book, untuk dilaksanakan dengan benar, tepat waktu dan berapapun biaya perawatan yang akan dikeluarkan tidak menjadi masalah, demi mempertahankan operasi generator engine tetap lancar tanpa pernah menganggur dan memperkecil/mencegah kerusakan yang terjadi (Life Time).

Pelaksanaan perawatan dan perbaikan yang dapat dilakukan pada generator engine:

1) Pelaksanaan perawatan dan perbaikan pada minyak lumas:

Pemeriksaan kondisi pelumas seperti kekentalan maupun warna dari minyak pelumas tersebut. Pemeriksaan kebocoran air pendingin pada dinding-dinding cylinder liner bagian dalam dan bagian luar. Pemeriksaan secara visual pada minyak lumas maupun pada pendinginannya.

2) Pelaksanaan perawatan dan perbaikan pada komponen generator engine:

Pembersihan, pemeriksaan, pengukuran, penganalisaan, penggantian material atau pengecekan fisik tahap pertama top overhaul yang meliputi material, kepala silinder, penekan katup lengkap, batang pendorong, katup isap dan buang, katup udara berjalan. Tahap kedua major overhaul, yang meliputi torak dan ring torak, batang torak, poros engkol, poros nok dan lain-lain..

3) Ketersediaan spare parts.

Ketersediaan spare parts di atas kapal MT. Martha Option sangat penting karena untuk 
A. Y Prasetya ${ }^{a}$ dan Tri Kismantoro ${ }^{b}$

mengatisipasi jika ada komponenkomponen yang rusak dan harus diganti. Jika tidak ada spare parts kemungkinan akan menghambat jalannya perawatan dan dapat mengakibatkan kerusakan pada komponen-komponen yang lain dalam suatu mesin.

Menurut hasil observasi ketersediaan spare parts di atas kapal MT. Martha Option sangat penting karena untuk mengatisipasi jika ada komponen-komponen yang rusak dan harus diganti. Jika tidak ada spare parts kemungkinan akan menghambat jalannya perawatan dan dapat mengakibatkan kerusakan pada komponen-komponen yang lain dalam suatu mesin.

Menurut hasil tanya jawab dengan KKM (Kepala Kamar Mesin) ketersediaan spare parts sangat penting, karena dengan tidak tersedianya spare parts yang kita perlukan sangat menghambat proses perawatan dan perbaikan suatu permesianan. Maka dari itu kita harus senantiasa melakukan pengecekan atas ketersediaan spare parts, jika tidak ada maka kita perlu melakukan permintaan ke kantor untuk pengadaan spare parts yang kita butuhkan.

\section{PENUTUP}

\section{Kesimpulan}

Berdasarkan dari hasil penelitian yang telah dilakukan di lapangan dan dari hasil uraian permasalahan yang telah dihadapi mengenai pecahnya cylinder liner pada generator engine di MT. Martha Option, maka dapat diambil beberapa simpulan sebagai berikut:

a. Pecahnya cylinder liner pada generator engine disebabkan oleh beberapa faktor yaitu kurangnya tekanan air pendingin, pelumasan yang tidak optimal dan kondisi cylinder liner yang sudah aus.

b. Pecahnya cylinder liner pada generator engine mengakibatkan pembakaran dalam cylinder liner tidak sempurna dan tenaga generator engine berkurang.

c. Perawatan dan perbaikan terhadap komponen generator engine, misalnya cylinder liner harus sesuai dengan jam kerja yang ada di manual book. Dan ketersediaan spare parts sangat penting untuk mencegah hal-hal yang tidak diinginkan jika nantinya ada perawatan yang memerlukan pergantian komponen tertentu.

\section{Saran}

Dari simpulan di atas maka Penulis dapat memberikan saran mengenai permasalahan yang dibahas dalam bab terdahulu yang mana saran tersebut semoga dapat dijadikan pedoman dalam menyelesaikan masalah yang terjadi di atas kapal.

a. Para Masinis sebaiknya sering melakukan perawatan dan pengontrolan terhadap tekanan air pendingin dengan perawatan pada kompresor karena rusaknya kompresor berpengaruh terhadap tekanan air pendingin, pelumasan yaitu dengan memperhatikan jam kerja dan kualitas minyak lumas dan cylinder liner sebaiknya diperiksa sesuai dengan jam kerja pada manual book, sehingga generator engine dapat berfungsi dengan baik sebagaimana yang diinginkan.

b. PMS (planning maintenance system) dijadikan budaya kerja. Perawatan komponen di generator engine harus sesuai dengan jam kerja yang ada dalam instruction manual book, serta jika ditemukan kelainan pada komponen generator engine harus segera diatasi agar kapal dapat beroperasi dengan lancar.

c. Selain itu, hendaknya para Masinis memperhatikan spare parts untuk komponen-komponen utama pada generator engine, sehingga pada saat terjadi kerusakan darurat sudah tersedia spare parts yang diperlukan pada saat itu. 


\section{DAFTAR PUSTAKA}

Christen, Knak. 1979. Diesel Motor Ships Engine and Machinery Text. Copenhagen: G.E.Cgad Publishers

Endrodi. 1985. Motor Diesel Penggerak Utama. Jakarta

Afrizal. 2014. Metode Penelitian Kualitatif. Jakarta: PT. Raja Grafindo

Joe. 2011. Kerusakan pada cylinder liner. $<$ URLhttp://joepencerahan.blogspot. com/2011/07/kerusakan-padacylinder-liner. Html>

Maleev, V.L. 1954. Diesel Engine Operating and Maintenance: The Construction, Operation, Maintenance and Repair of Modern Disel Engine. New York: McGraw-Hill Book Company

Maneen, P.V. 1987. Motor Diesel Kapal. Jakarta: PT. Triasko Madra

Mukhtar. 2013. Metode Praktis Penelitian Deskriptif Kualitatif. Jakarta: Referensi (GP Press Group)

Sugiyono. 2009. Metode Penelitian Kuantitatif, Kualitatif, dan $R \& D$. Bandung: CV. Alfabeta

Sunarta, Nakula. dan Furuhama, Shoichi. 2002. Motor Serba Guna. Jakarta: PT. Pradnya Paramita

Tim Penyusun PIP Semarang. 2009. Pedoman Penyusunan Penelitian. Semarang: Politeknik Ilmu Pelayaran

Tjahjono, Tri. 2005. Analisis Keausan Pada Dinding Silinder Mesin Diesel. 78-83

Yanmar. Manual Book: Yanmar Diesel Engine. Model M220 (A) (L). Operation manual. Yanmar Corp 